\title{
Association between single-nucleotide polymorphisms within candidate genes and fertility in Landrace and Duroc pigs
}

\author{
Nina Hårdnes Tremoen 1,3*0, Maren Van Son², Ina Andersen-Ranberg ${ }^{2}$, Eli Grindflek², \\ Frøydis Deinboll Myromslien', Ann Helen Gaustad ${ }^{1,2}$ and Dag Inge Våge ${ }^{3}$
}

\begin{abstract}
Finding effective predictors of traits related to boar fertility is essential for increasing the efficiency of artificial insemination systems in pig breeding. The objective of this study was to find associations between single-nucleotide polymorphisms (SNPs) within candidate genes and fertility in the breeds Landrace and Duroc. Animals with breeding values for total number of piglets born, were re-sequenced for exonic regions of 14 candidate genes related to male and female fertility using samples from 16 Landrace boars and 16 Duroc boars (four with high and four with low breeding value of total number of piglets born for each breed for male fertility, and the same for female fertility) to detect genetic variants. Genotyping for the detected SNPs was done in 619 Landrace boars and 513 Duroc boars. Two SNPs in BMPR1 and one SNP in COX-2 were found significantly associated with the total number of piglets born in Landrace. In Duroc, two SNPs in $P L C_{Z^{\prime}}$ one SNP in VWF and one SNP in ZP3 were found significantly associated with total number of piglets born. These SNPs explained between $0.27 \%$ and $1.18 \%$ of the genetic variance. These effects are too low for being used directly for selection purposes but can be of interest in SNP-panels used for genomic selection.
\end{abstract}

Keywords: Boar, Candidate genes, Fertility, SNP

\section{Findings}

The traditional measurements of boar fertility are pregnancy rate and litter size. However, these measurements are retrospective and highly influenced by the breeding management and the genetic potential of the sows. Finding effective predictors of traits related to boar fertility would allow for excluding the less fertile boars from pig production and improving the breeding system.

Several genes have been proposed as candidate genes for male fertility, including phospholipase $\mathrm{C}$ zeta $(P L C z)$ and cyclooxygenase isoenzyme type 2 (COX-2) [1]. Also, when it comes to female fertility, several genes are involved such as bone morphogenic protein 15 (BMP15), bone morphogenic protein receptor 1B (BMPR1B), and growth differentiation factor 9 (GDF9) [2-4]. The

\footnotetext{
*Correspondence: nina.tremoen@inn.no

1 Department of Biotechnology, Inland Norway University of Applied

Sciences, 2318 Hamar, Norway

Full list of author information is available at the end of the article
}

estrogen receptors 1 and 2 (ESR1 and ESR2) have proved to be involved in both male and female reproduction $[5,6]$. Samples from sows were not included in the current study, but genes linked to female reproduction were included to investigate the boars as maternal grandsires. Moreover, all the genes were analysed in both breeds.

In this study, we analysed male fertility of the boars as sire of their litters, and female fertility measured as fertility of the boars' daughters for detection of genetic variants. The variance components were estimated and the heritabilities were estimated by dividing female or male variance by the total variance. The estimated variance components and estimated breeding values (EBVs) for total number of piglets born (TNB) were calculated using a univariate animal repeatability model and included both the direct genetic effect (male fertility) and sire effect based on daughter fertility (female fertility). In addition, herd $\times$ year, parity to the mother (parity_m), parity of the sow (parity), season as fixed effects, age of sow at farrowing within parity as fixed regression effects 
(age(parity), age ${ }^{2}$ (parity)) and litter and animal (ID, ID sire) as random effects were included in the following model:

$$
\begin{aligned}
\mathrm{y}= & \text { herd } \times \text { year }+ \text { parity_m }+ \text { parity }+ \text { season } \\
& + \text { age }(\text { parity })+\operatorname{age}^{2}(\text { parity })+\text { litter }+ \text { ID }+ \text { ID_sire }+\mathrm{e}
\end{aligned}
$$

Only results from purebred litters were used to estimate (co-)variance components and breeding values, and 86,539 litters from Landrace and 16,819 litters from Duroc had records on TNB. Pedigrees were traced back seven generations and included 61,293 and 13,480 animals for Landrace and Duroc, respectively.

The candidate genes were chosen based on previous reported involvement in fertility or in pathways related to reproduction. In total, 14 candidate genes were selected (Additional file 1), seven specific for male fertility, five specific for female fertility and two important for both male and female fertility. The coding regions of 14 genes were sequenced using samples from 16 Landrace and 16 Duroc boars selected based on their EBVs, to identify genetic variation in these candidate genes. Eight Landrace boars and eight Duroc boars (four with high and four with low breeding value for each breed) were selected based on male fertility. The other group (with equal number of animals) was selected based on female fertility. DNA was isolated from sperm cells at BioBank, Hamar, Norway using the Maxwell 16 Tissue DNA Purification Kit (Promega, Madison, WI, USA) and polymerase chain reaction (PCR) primers were designed to amplify the exons of the selected genes using Primer3 [7] (for primer sequences, see Additional file 2). PCR was performed using HOT FIREPol DNA Polymerase (Solis BioDyne, Tartu, Estonia) and analysed on ABI 3130XL (Applied Biosystems, Foster City, CA, USA). The PCR products were sequenced using the BigDye ${ }^{\circledR}$ Terminator v3.1 kit (Applied Biosystems) analyzed on ABI 3130XL (Applied Biosystems). Resulting sequences were aligned and screened for SNPs using the programs phred, phrap and consed $[8,9]$. Out of the 14 re-sequenced genes, primers for 52 SNPs were designed. Additionally, one extra SNP (Von Willenbrand factor, $V W F)$ was added to the analysis based on previous results [10]. SNPs were filtered based on call rate $(>0.97)$, minor allele frequency (MAF) $(>0.01)$ and deviation from Hardy-Weinberg equilibrium $(\mathrm{HWE}<0.0001)$, leaving 36 SNPs for genotyping.

For the association study of male and female fertility, 619 Landrace boars and 513 Duroc boars were included. All the boars in this study have been used in AI during the last 10 years, with 107,640 litters in Landrace (mean $\mathrm{TNB}=13.7 \pm 3.6$ ) and 16,849 litters in Duroc (mean TNB $=9.3 \pm 2.9$ ). The EBVs of direct genetic effect (male fertility) and maternal genetic effect (female fertility) are the phenotypes used for association. Genomic DNA was extracted from blood or semen using BioSprint DNA Kit (Qiagen, Hilden, Germany), assay design was done using Assay Design Suite software (Agena Biosciences, San Diego, CA, USA), and genotyping was done using the Sequenom massARRAY platform (Agene Biosciences) at CIGENE, Norwegian University of Life Sciences. Newly detected SNPs were submitted to the European Variant Archive (EVA) (https://www.ebi.ac.uk/eva) with accession number PRJEB23828.

Genotype effects were estimated using the following animal model in ASReml (v. 3.0.22.2):

$$
\mathrm{y}=\mu+\mathrm{SNP}+\mathrm{ID}+\mathrm{e}
$$

where y is EBV for TNB (male or female fertility), SNP genotype ( $\mathrm{AA}, \mathrm{AB}$ or $\mathrm{BB}$ ) was fitted as a fixed effect and animal ID was fitted as a random effect. A pedigree-based relationship matrix was used, and a P-value $<0.05$ was considered significant. The genetic variance explained by a SNP was calculated in ASReml as $2 p(1-p) \alpha^{2}$, where $\alpha$ is the allele substitution effect, divided by the additive genetic variance.

In Landrace, the analyses showed two significant SNPs, rs331082315 in BMPR1 and rs337596396 in COX-2 (male fertility) (Table 1), and two significant SNPs, rs45435443 in BMPR1 and rs337596396 in COX-2 (female fertility) (Table 2). In Duroc, the analyses resulted in three significant SNPs, $r s 338483233$ in $P L C_{z}, r s 328291649$ in $V W F$ and $r s 339149260$ in ZP3 (male fertility) (Table 1) and two significant SNPs, rs338483233 and $r s 196952431$ in $P L C_{z}$ (female fertility) (Table 2). All the significant SNPs had previously been annotated in the pig genome.

For Landrace, the SNP in BMPR1B was found significantly associated for both female and male fertility, meaning that this gene might be important for both male and female fertility traits. The gene family member $B M P 1$ has previously been found differentially expressed in both Landrace and Duroc boars with high/ low levels of sperm DNA fragmentation [10] and several BMPs have been found important for fertility earlier [11].

Both $P L C_{z}$ and $C O X-2$ are involved in spermatogenesis through the prostaglandin production and significant association between polymorphisms within the COX-2 gene and litter size has previously been reported $[1,12]$. In this study, a significant SNP within the $P L C_{z}$ gene was found in Duroc pigs, related to both male and female fertility. This SNP was not significant in Landrace, however, a SNP within the COX-2 gene was found significant for male and female fertility in Landrace. 
Table 1 Significant SNPs for total number of piglets born as a male fertility trait

\begin{tabular}{|c|c|c|c|c|c|}
\hline Breed & $\mathrm{NL}$ & $\mathrm{NL}$ & ND & ND & ND \\
\hline Gene & $B M P R 1 B$ & $\operatorname{cox}-2$ & $Z P 3$ & $P L C_{z}$ & VWF \\
\hline Genbank & NW_003610967.1 & NW_003300644.3 & NM_213893.1 & NM_214350.1 & NM_001246221.1 \\
\hline Chromosome & 8 & 9 & 3 & 5 & 5 \\
\hline Position & 133743941 & 140252549 & 9840522 & 57682420 & 67005497 \\
\hline Genotype & {$[\mathrm{C} / \mathrm{T}]$} & {$[\mathrm{C} / \mathrm{T}]$} & {$[\mathrm{G} / \mathrm{T}]$} & {$[\mathrm{A} / \mathrm{G}]$} & {$[\mathrm{C} / \mathrm{T}]$} \\
\hline SNP database & rs331082315 & rs337596396 & rs339149260 & rs338483233 & rs328291649 \\
\hline Genetic variance (\%) & 0.92 & 43,101 & 0.55 & 0.71 & 0.91 \\
\hline P-value & 0.010 & 0.010 & 0.018 & 0.025 & 0.010 \\
\hline Minor allele frequency (MAF) & 0.21 & 0.48 & 0.05 & 0.44 & 0.43 \\
\hline Hardy-Weinberg equilibrium (HWE) & 0.58 & 0.78 & 0.19 & 0.89 & 0.74 \\
\hline Consequence & 3 prime UTR variant & 3 prime UTR variant & Intron variant & Missense variant & Missense variant \\
\hline
\end{tabular}

The significant SNPs for Landrace (NL) and Duroc (ND) boars based on their performance as father (male fertility). Positions are given according to pig genome build Sscrofa10.2 obtained from the ENSEMBL web site (https://www.ensembl.org)

Table 2 Significant SNPs for total number of piglets born as a female fertility trait

\begin{tabular}{|c|c|c|c|c|}
\hline Breed & $\mathrm{NL}$ & $\mathrm{NL}$ & ND & ND \\
\hline Gene & $B M P R 1 B$ & $\operatorname{cox}-2$ & $P L C_{z}$ & $P L C_{z}$ \\
\hline Genbank & NW_003610967.1 & NW_003300644,3 & NM_214350.1 & NM_214350.1 \\
\hline Chromosome & 8 & 9 & 5 & 5 \\
\hline Position & 133765484 & 140252549 & 57682420 & 57693191 \\
\hline Genotype & {$[\mathrm{A} / \mathrm{G}]$} & {$[\mathrm{C} / \mathrm{T}]$} & {$[A / G]$} & {$[\mathrm{C} / \mathrm{T}]$} \\
\hline SNP database & rs45435443 & rs337596396 & rs338483233 & rs196952431 \\
\hline Genetic variance (\%) & 0.27 & 0.67 & 0.82 & 0.71 \\
\hline P-value & 0.039 & 0.042 & 0.016 & 0.030 \\
\hline Minor allele frequency (MAF) & 0.05 & 0.48 & 0.44 & 0.43 \\
\hline Hardy-Weinberg equilibrium (HWE) & 0.82 & 0.78 & 0.89 & 0.62 \\
\hline Consequence & Synonymous variant & 3 prime UTR variant & Missense variant & Synonymous variant \\
\hline
\end{tabular}

The significant SNPs for Landrace (NL) and Duroc (ND) boars based on the performance of their daughters (female fertility). Positions are given according to pig genome build Sscrofa10.2 obtained from the ENSEMBL web site (https://www.ensembl.org)

The zona pellucida protein 3 (ZP3) has been reported to initiate the sperm binding and to induce the acrosome reaction in sperm cells in humans [13]. In this study, a significant SNP within the ZP3 gene was found associated with male fertility in Duroc.

A significant SNP was found associated to male fertility in VWF in Duroc. VWF has been suggested to have an effect in the angiogenesis in the porcine oviduct in response to seminal plasma, to be involved in the early stage of endothelium activation and to be sign of vascular bed remodelling in the oviduct $[14,15]$. No association with female fertility was found, despite the previously association to sperm DNA fragmentation [10].

The SNPs explained between 0.27 and $1.18 \%$ of the genetic variance for TNB. The low genetic effects for TNB is supported by other association studies for litter size in pigs $[16,17]$. In highly selected breeds such as
Landrace, any gene variant with a major effect on fertility is expected to be fixed. Also, the moderate heritability for litter size [e.g. 18] indicate a true quantitative nature of this traits. Only a subset of possible candidate genes was included in this study, so there might be other genes with larger effects. However, GWASstudies in pigs have so far not identified any major QTL related to fertility [19]. The genetic effects obtained in this study are too low to be used for selection purposes directly, but might be useful in a whole genome SNPpanel for genomic selection, since these SNPs would be located closer to causal variants than SNPs mainly selected to be evenly spaced SNP across the genome.

The current study suggests a role of the genes $B M P R 1, C O X-2, P L C_{z}, V W F$ and $Z P 3$ in total number of piglets born. The SNPs explain between 0.27 and $1.18 \%$ of the genetic variance for TNB, suggesting a limited 
contribution to the total genetic variation of the trait. Furthermore, significant SNP-effects from fixed effects models are generally overestimated, which probably means that the explained variation is overestimated. Further studies are needed to discover the functional mutations and to find other genes contributing to the genetic variation of litter size. The SNPs obtained might, however, be of interest in SNP-panels used for genomic selection, since they are likely more associated to these traits than randomly selected SNP-markers.

\section{Supplementary information}

Supplementary information accompanies this paper at https://doi. org/10.1186/s13028-019-0493-x.

Additional file 1. Overview over 14 genes used for association between SNP within candidate genes and fertility in Landrace and Duroc pigs.

Additional file 2. Primer sequences.

\section{Abbreviations}

BMP15: bone morphogenic protein 15; BMPR1B: bone morphogenic protein receptor 1B; COX-2: cyclooxygenase isoenzyme type 2; EBV: estimated breeding value; ESR1: estrogen receptor 1; ESR2: estrogen receptor 2; GDF9: growth differentiation factor; HWE: Hardy-Weinberg equilibrium; MAF: minor allele frequency; PLCZ: phospholipase C zeta; SNP: single nucleotide polymorphism; TNB: total number of piglets born; VWF: Von Willenbrand factor; ZP3: zona pellucida protein 3.

\section{Acknowledgements}

The authors want to thank Kristil Kindem Sundsaasen (CIGENE, Norwegian University of Life Sciences, Ås), Hanne Hamland (Norsvin) and Biobank AS (Hamar) for laboratory assistance.

\section{Prior publication}

Data have not been published previously.

\section{Authors' contributions}

NHT has contributed in experimental design, laboratory work, data processing and statistics and writing the manuscript. MvS and DIV have contributed in experimental design, data processing and writing the manuscript. IAR has contributed in experimental design, calculation of breeding values and writing the manuscript. EG and AGH have contributed in experimental design and writing the manuscript. FDM has contributed in experimental design and statistics and writing the manuscript. All authors read and approved the final manuscript.

\section{Funding}

This study was partly funded by the Norwegian Research Council (Grant Number 207568).

\section{Availability of data and materials}

The datasets used and/or analysed during the current study are available from the corresponding author on reasonable request.

\section{Ethics approval and consent to participate}

This study did not require official or institutional ethical approval. All animals were cared for in line with laws, internationally recognized guidelines and regulations for keeping pigs in Norway (The Animal Protection Act of December 20th, 1974, the Animal Welfare Act of June 19th, 2009 and the Regulations for keeping of pigs in Norway of February 18th, 2003). The animals used in this study were Al boars kept as a routine by Norsvin's breeding program.

\section{Consent for publication}

Not applicable.

\section{Competing interests}

The authors declare that they have no competing interests.

\section{Author details}

${ }^{1}$ Department of Biotechnology, Inland Norway University of Applied Sciences, 2318 Hamar, Norway. ${ }^{2}$ Norsvin, Storhamargata 44, 2317 Hamar, Norway. ${ }^{3}$ Department of Animal and Aquacultural Sciences, Centre for Integrative Genetics (CIGENE), Faculty of Biosciences, Norwegian University of Life Sciences, 1432 Ås, Norway.

Received: 1 February 2019 Accepted: 25 November 2019

Published online: 03 December 2019

\section{References}

1. Kaewmala K, Uddin MJ, Cinar MU, Grosse-Brinkhaus C, Jonas E, Tesfaye $D$, et al. Investigation into association and expression of PLCz and COX-2 as candidate genes for boar sperm quality and fertility. Reprod Domest Anim. 2012:47:213-23.

2. De Castro FC, Cruz MH, Leal CL. Role of growth differentiation factor 9 and bone morphogenetic protein 15 in ovarian function and their importance in mammalian female fertility - a review. AJAS. 2016;29:1065-74.

3. Paradis F, Novak S, Murdoch GK, Dyck MK, Dixon WT, Foxcroft GR. Temporal regulation of BMP2, BMP6, BMP15, GDF9, BMPR1A, BMPR1B, BMPR2 and TGFBR1 mRNA expression in the oocyte, granulosa and theca cells of developing preovulatory follicles in the pig. Reproduction. 2009:138:115-29.

4. Våge DI, Husdal M, Kent MP, Klemetsdal G, Boman IA. A missense mutation in growth differentiation factor 9 (GDF9) is strongly associated with litter size in sheep. BMC Genet. 2013;14:1.

5. Gunawan A, Kaewmala K, Uddin MJ, Cinar MU, Tesfaye D, Phatsara C, et al. Association study and expression analysis of porcine ESR1 as a candidate gene for boar fertility and sperm quality. Anim Reprod Sci. 2011:128:11-21.

6. Gunawan A, Cinar MU, Uddin MJ, Kaewmala K, Tesfaye D, Phatsara C, et al. Investigation on association and expression of ESR2 as a candidate gene for boar sperm quality and fertility. Reprod Domest Anim. 2012;47:782-90.

7. Untergasser A, Cutcutache I, Koressaar T, Ye J, Faircloth BC, Remm M, et al. Primer3-new capabilities and interfaces. Nucleic Acids Res. 2012;40:e115.

8. Gordon D, Abajian C, Green P. Consed: a graphical tool for sequence finishing. Genome Res. 1998;8:195-202.

9. Ewing B, Green P. Base-calling of automated sequencer traces using phred. II. Error probabilities. Genome Res. 1998;8:186-94.

10. Van Son M, Tremoen NH, Gaustad AH, Myromslien FD, Vage DI, Stenseth $E B$, et al. RNA sequencing reveals candidate genes and polymorphisms related to sperm DNA integrity in testis tissue from boars. BMC Vet Res. 2017;13:362.

11. Shimasaki S, Zachow RJ, Li D, Kim H, lemura S, Ueno N, et al. A functional bone morphogenetic protein system in the ovary. Proc Natl Acad Sci USA. 1999;96:7282-7.

12. Sironen Al, Uimari P, Serenius T, Mote B, Rothschild M, Vilkki J. Effect of polymorphisms in candidate genes on reproduction traits in Finnish pig populations. J Anim Sci. 2010;88:821-7.

13. Chiu PC, Wong BS, Chung MK, Lam KK, Pang RT, Lee KF, et al. Effects of native human zona pellucida glycoproteins 3 and 4 on acrosome reaction and zona pellucida binding of human spermatozoa. Biol Reprod. 2008;79:869-77.

14. Zanetta L, Marcus SG, Vasile J, Dobryansky M, Cohen H, Eng K, et al. Expression of Von Willebrand factor, an endothelial cell marker, is upregulated by angiogenesis factors: a potential method for objective assessment of tumor angiogenesis. Int J Cancer. 2000;85:281-8.

15. Krawczynski K, Kaczmarek MM. Does seminal plasma affect angiogenesis in the porcine oviduct? Reprod Biol. 2012;12:347-54.

16. Bergfelder-Druing S, Grosse-Brinkhaus C, Lind B, Erbe M, Schellander $\mathrm{K}$, Simianer $\mathrm{H}$, et al. A genome-wide association study in large white and landrace pig populations for number piglets born alive. PLOS ONE. 2015;10:e0117468. 
17. Holm B, Bakken M, Vangen O, Rekaya R. Genetic analysis of age at first service, return rate, litter size, and weaning-to-first service interval of gilts and sows. J Anim Sci. 2005;83:41-8.

18. Trenhaile MD, Petersen JL, Kachman SD, Johnson RK, Ciobanu DC. Long-term selection for litter size in swine results in shifts in allelic frequency in regions involved in reproductive processes. Anim Genet. 2016;47:534-42.
19. Sell-Kubiak E, Duijvesteijn N, Lopes MS, Janss LL, Knol EF, Bijma P, et al. Genome-wide association study reveals novel loci for litter size and its variability in a large white pig population. BMC Genomics. 2015;16:1049.

\section{Publisher's Note}

Springer Nature remains neutral with regard to jurisdictional claims in published maps and institutional affiliations.
Ready to submit your research? Choose BMC and benefit from:

- fast, convenient online submission

- thorough peer review by experienced researchers in your field

- rapid publication on acceptance

- support for research data, including large and complex data types

- gold Open Access which fosters wider collaboration and increased citations

- maximum visibility for your research: over $100 \mathrm{M}$ website views per year

At BMC, research is always in progress.

Learn more biomedcentral.com/submissions 